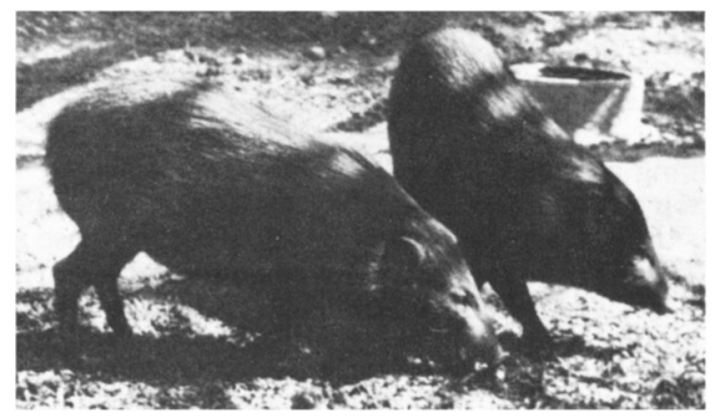

\title{
Pygmy Hog
}

in

Assam

Early in 1971 the pygmy hog, widely believed by scientists to be extinct (though many people in the Himalayan foothills must have known otherwise) was 're-discovered' in the Manas Sanctuary in north-west Assam (Oryx September 1971). Since then attempts to breed the species in captivity have been largely unsuccessful, and nothing has been done to protect them in the wild.

In the first of the Jersey Wildlife Preservation Trust's new series of Special Scientific Reports, William Oliver, who spent three months in the field studying the pygmy hog Sus salvanius and hispid hare Caprolagus hispidus situations in north-west Assam, shows how bleak is the outlook for both species owing to the continuing loss of their habitat. Since this consists of tall grassscrub savanna, in flat, well-drained and thinly forested country, it has been under tremendous pressure for settlement and agriculture in the past twenty years or so. What remains for the pygmy hogs is a series of small discrete areas within declared forest boundaries, though nearly all have suffered also from dry-season burning and other forestry practices.

Burning not only greatly reduces the quality of the habitat, but forces the hogs to seek cover in the surrounding agricultural land and tea estates-with predictable results. Only the few small areas left unburned, usually by chance, support the tiny 'float' populations of both species during the two to three months after each burning until the vegetation grows again after the early rains. But since other wildlife naturally concentrates in whatever cover remains unburned during this period, these areas may also be extensively poached. Hunting thus remains a serious problem despite Assam's ratification in 1977 of the Indian Wildlife (Protection) Act, 1972, which accords both species (but not their habitat) full protection. Oliver saw the remains of five pygmy hogs and one hispid hare that had been killed in this way in the Barnadi Reserve Forest. In another, the Rowta Reserve Forest, forestry officials burn virtually all

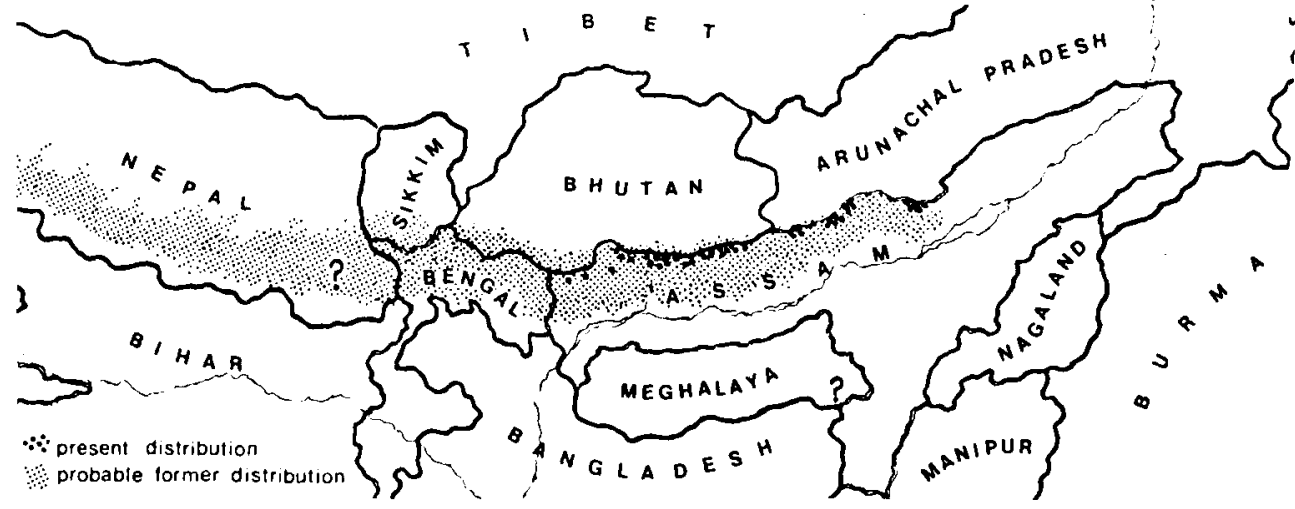




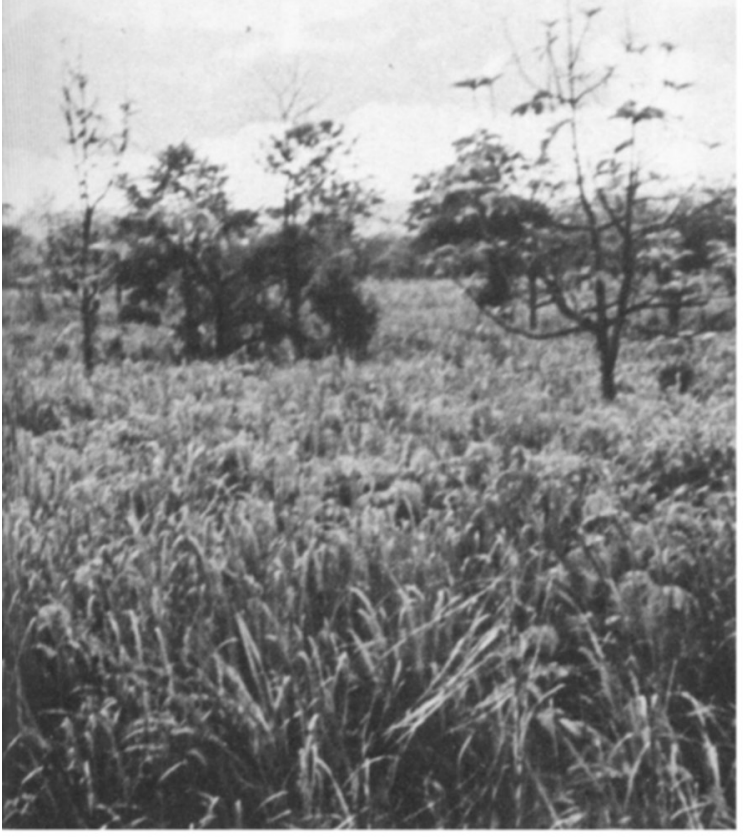

THATCH SCRUB before burning

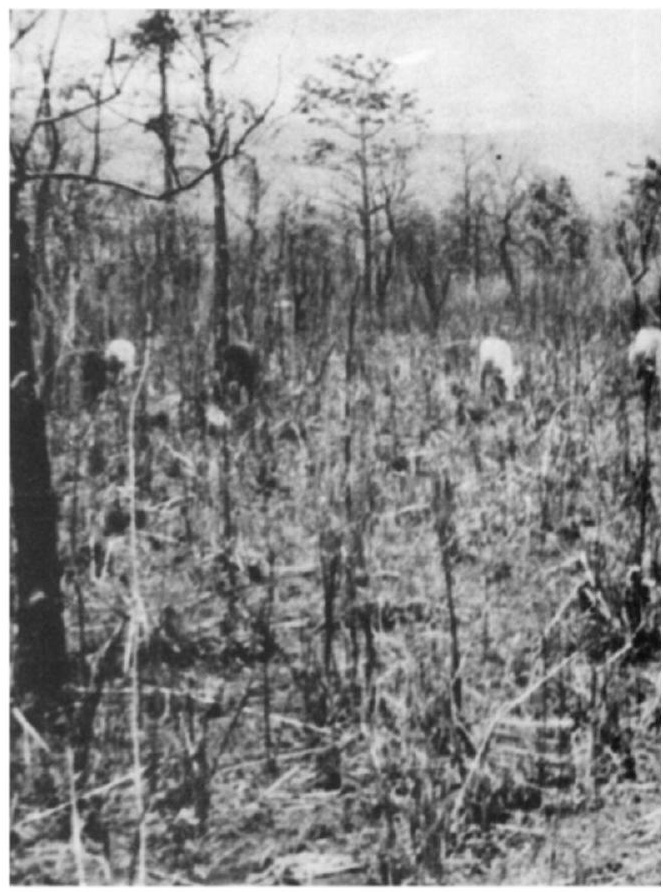

... and after

available habitat every year and unless this is stopped the hogs are certain to disappear. Similarly in Khalingdaur Reserve Forest where both species occurred until recently, herdsmen with grazing rights regularly and illegally burn some nine square miles of otherwise suitable habitat and have now certainly exterminated both species. In Manas Sanctuary, the most important remaining area for both species, the populations are kept down by deliberate early burning to minimise the risk of later accidental burning which is potentially more destructive to forest. Since Manas is the only area where their habitat is legally protected, this is extremely unsatisfactory.

Thus, virtually nothing has been done to preserve either species in the wild state since their coincidental and rather dramatic reappearance in northwestern Assam in March, 1971. Moreover, none of the attempts to breed pygmy hogs in captivity in Assam has succeeded in establishing a viable captive population, and Assam's ratification of the 1972 Act makes it difficult now to get more breeding stock. The female of the pair taken to Jersey Zoo in 1976 died after producing a litter of four males and one female, and the young female died also. With both species now reduced in the wild to half-a-dozen or so fragmentary populations, their future is indeed precarious.

\section{Blind Dolphins Increasing}

The susu, the blind dolphin of the Indus river in Pakistan, is slowly building up its numbers in a reserve created for it. Ten years ago it was feared extinct, but in $1969770 \mathrm{a}$ Swiss expedition found some, and a count later gave an estimate of about 150 in one area. Now, after a 2-year ecological study supported by WWF, a census in May 1978 put the numbers at 240 , including over 40 young and a further increase is expected this year. The Sind Wildlife Management Board has installed four game wardens who patrol the reserve and deal firmly with poachers. 